\title{
The use of ISO standards in the hospitality industry: a comparative analysis of European clusters
}

\author{
Viktoriia Levkulych ${ }^{1}$, Alexander Momot $^{2},{ }^{*}$, \\ ${ }^{1}$ Candidate of Economic Sciences, Department of Accounting and Audit, Uzhhorod National University, \\ Uzhhorod, Ukraine \\ ${ }^{2}$ Doctor of Sciences (Economic), Department of Management, South-Russian Institute of Management of \\ RANEPA, Rostov-on-Don, Russian Federation
}

\begin{abstract}
The article provides a comparative analysis of the use of ISO standards in the hospitality industry among 46 European countries. The study confirms the hypothesis that the more actively ISO 9001 standards are distributed in European countries, the higher is the level of implementation in the hospitality industry and other ISO standards for management systems (ISO 14001, ISO 45001, etc.). The degree of ISO standards distribution can be a non-formal criterion of the degree of population's involvement in the technological, technical, organizational culture of the European society. The degree of correlation relationship between the Rating of countries by the number of issued ISO 9001 certificates and the Travel \& Tourism Competitiveness Index (TTCI), Global Competitiveness Index (GCI) and Global Innovation Index (GII) rankings of countries is examined. The authors offer the clusterization of the European countries according to three criteria: the number of obtained ISO 9001 certificates; the time of accession to the EU (and the existence of the membership status of countries, candidate countries or potential candidates); the presence of common characteristics according to the technical, socioeconomic, sociological and technological level, as well as moral and ethical norms formed in these countries during the existence of two political and socioeconomic system.
\end{abstract}

${ }^{*}$ Corresponding author: mazka83@mail.ru 


\section{Introduction}

The importance of the role of ISO standards for management systems is recognized in the global community by most experts. Scholars are increasingly arguing that ISO standards have an impact on the sustainable development of society and are linked to the growth of wellbeing via such indicators as GDP per capita, the Human Development Index, and other economic indicators [1,2]. However, despite the fact that the ISO 9000 and 14000 series of standards have recently tended to decrease [3,4], the scope of their use is expanding, increasingly covering various industries, including tourism and the hotel and restaurant business.

Accordingly, we are observing an increasing role of ISO certificates in the global hospitality industry, influencing not only the possibility of improving the industry's efficiency but also providing a relevant means of survival in the face of growing competition, environmental change and the threats posed by the COVID-19 pandemic. The pandemic has largely aggravated the operating environment of the hospitality industry. In the conditions of a several-fold reduction in the profitability of the industry, as a result of the continuing practice of restrictions, an enormous role is assigned to the ability of the hospitality industry to reduce all types of costs, expand the list of services, find new effective ways to attract residents and non-residents, adequate to the conditions of the external and internal environment. The ability to withstand these conditions depends on the potential accumulated over many years, including through the use of effective management systems.

\subsection{Brief Literature Review}

The issues of studying the application of ISO standards in the enterprises of different countries were considered in the works of Fonseca [5,6]. The role of ISO standards in implementing international trade was discussed in Borial [7]

The possibilities of clustering European countries according to the extent of ISO 9001 certification were discussed in the works of Franceschini [8]. The analysis of the increased attention to ISO standards in other management areas was addressed in Berényi L. The impact of ISO 9001 standards on labor productivity was studied in the article by Albulescuab [9]. Research on integrated management systems in a country with a relatively low number of ISO 9001 and ISO 14001 certifications was conducted in the works by Bernardo [10]; Bouranta N. et al.,[11]. The role of standards in the tourism business and their impact on small tourism enterprises and hospitality industry organizations were discussed in Augustyn [12] and Varotsis [13], providing the reasons for the reduced interest in ISO standards by individual companies, for instance, Greek companies. Mohammad Reza Davahli [14] reviewed the literature related to the research of current topics and methods in the hospitality industry in the context of the COVID-19 pandemic.

However, currently, there is insufficient research (except the popular ISO 9001 standards) and published scientific papers concerning the distribution of other types of ISO standards on management systems in the context of clusters in European countries as a whole, including the hospitality industry.

\subsection{Problem Formulation}

One of the directions in the research is devoted to a comparative analysis of applying ISO standards for management systems (Management System Standards (MSS) in the hospitality industry in countries with transitional economies.

Given the high popularity of the ISO 9001 model in the world and Europe and the emergence of its more effective version of ISO 9001:2015, which has a unified high-level structure HLS and long-term perspective, as well as the threats posed by the outburst of the 
COVID-19 pandemic, the purpose of the present study is to identify the degree of correlation between the number of ISO certificates and other factors, in order to develop integrated management systems, which combine the benefits of different ISO standards, and allow for increased efficiency and safety of the hospitality industry.

The following objectives have been specified in the paper:

1) To determine whether there is a correlation between the Ranking of countries according to the number of the most popular ISO 9001:2015 certificates issued in the world as a whole for all industries and the Ranking of the number of ISO certificates in the hospitality industry. To confirm the hypothesis that the more actively ISO 9001 standards are distributed in the countries, the higher the level of implementation in the hospitality industry and other management system standards in that country.

2) To determine the degree of correlation between the Rating of countries by the number of ISO 9001:2015 certificates issued and the Travel \& Tourism Competitiveness Index (TTCI), Global Competitiveness Index (GCI), Global Innovation Index (GII) country rankings.

3) To verify the distribution of the number of ISO MSS certificates across the clusters of European countries, formed on the basis of different models of socioeconomic development and management systems.

\section{Research Methods}

The research object included 49 countries located on the territory of the European part of the Eurasian continent, members of the European Union and the Union of Europe. Based on the studies by Probald and Szabo [15], Liptak [16], Stehrer [17], and the official websites of the European Union, Council of Europe, ISO member states, we have formed three clusters:

1) Countries with developed market economies that pioneered the formation of the EU or joined it before 2004, including Austria, Belgium, Denmark, Finland, France, Germany, Greece, Ireland, Italy, Luxembourg, Malta, the Netherlands, Portugal, Spain, Sweden, the United Kingdom (which left the EU on 01.02.2020), and the Republic of Cyprus: Austria, Belgium, Denmark, Finland, France, Germany, Greece, Ireland, Italy, Luxembourg, Malta, Netherlands, Portugal, Spain, Sweden, the United Kingdom (which left the EU on 01.02.2020) and the Republic of Cyprus, as well as other developed countries in the European Economic Area: Iceland, Norway, Switzerland.

2) Countries with transitional economies that joined the EU after 2004: Bulgaria, Croatia, Czech Republic, Estonia, Hungary, Latvia, Lithuania, Poland, Romania, Slovakia, Slovenia. This cluster also includes Candidate countries: Albania, Montenegro, North Macedonia, Serbia, Turkey; Potential candidates - Bosnia and Herzegovina.

3) Countries with transitional economies belonging to the Council of Europe and located partially or wholly on the European territory and were part of the USSR before 1991: Armenia, Azerbaijan, Belarus, Georgia, Kazakhstan, Moldova, Russia, Ukraine. Each of the countries in Group 3 has its own vector of political and economic development but they all withdrew from the former Soviet Union and have their own model of state-building in the post-Soviet space. In the countries that were part of the Soviet Union before 1991, a certain system of management [18] has developed over the course of their existence together, based on a mentality that differs significantly from that of the citizens in the countries of old Europe.

In contrast to the previously suggested variants of clustering (Franceschini $\mathrm{F}$. et al., Berényi L.) the three clusters we propose have been grouped according to the following three criteria: 
1) the number of certificates;

2) the time of their accession to the EU (and the presence of the membership status, candidate countries or potential candidates);

3) the presence of common characteristics on the technical, socioeconomic, sociological and technological level, as well as moral and ethical norms formed in these countries during the existence of two political and socioeconomic systems.

\section{Results}

\subsection{Dynamics of changes in ISO MSS standards}

To conduct a study of the distribution degree of ISO standards in the hospitality industry, we have taken the standards, which are the most popular according to the International Accreditation Forum (IAF) and are listed in the annual review of ISO Survey of Certifications. The general dynamics of ISO MSS certificates development within five years has amounted to $117 \%$ (Table 1), and the share in the total number of the issued certificates in the world has increased from $0,43 \%$ in 2015 to $0,55 \%$ in 2019 (Fig. 1).

We have observed a slow increase in the number of relatively new management system standards, such as ISO 27001, ISO 45001, ISO 50001, ISO 22301, ISO 28000, ISO 39001. Their number has increased significantly after the issuance of ISO 9001:2015, which received a unified structure of higher level (HLS - Higher Level Structure), providing the basis for the creation of integrated management systems (Fonseca, L. Domingues, J.P.).

Table 1. Total valid certificates. Source: [14]

\begin{tabular}{|c|c|c|c|c|c|c|c|c|c|c|}
\hline & \multicolumn{2}{|c|}{2015} & \multicolumn{2}{|c|}{2016} & \multicolumn{2}{|c|}{2017} & \multicolumn{2}{|c|}{2018} & \multicolumn{2}{|c|}{2019} \\
\hline & 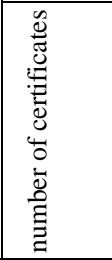 & 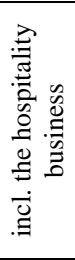 & 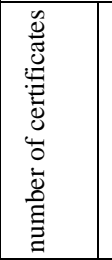 & 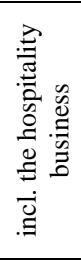 & 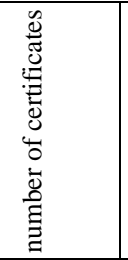 & 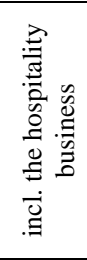 & 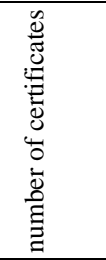 & 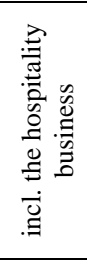 & 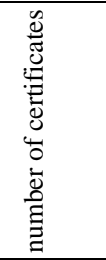 & 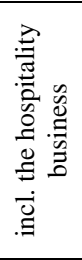 \\
\hline ISO 9001:2015 & 1034180 & 4340 & 1105937 & 5398 & 1058504 & 3565 & 878664 & 4429 & 883521 & 4631 \\
\hline ISO 14001:2015 & 319496 & 1772 & 346147 & 1786 & 3626 & 01555 & 307059 & 2135 & 312580 & 2276 \\
\hline ISO 27001:2013 & 27536 & 6 & 33290 & 7 & 3950 & 10 & 31910 & 9 & 36362 & 25 \\
\hline ISO 22000:2018* & 32061 & - & $\begin{array}{l}3213 \\
9\end{array}$ & - & 32722 & - & 32120 & - & 33502 & - \\
\hline ISO 45001:2018 & - & - & - & - & - & - & 11952 & 43 & 38654 & 129 \\
\hline $\begin{array}{l}\text { ISO } \\
50001: 2011 / 2018\end{array}$ & 11985 & 7 & $\begin{array}{l}2021 \\
6\end{array}$ & 21 & 21501 & 23 & 18059 & 33 & 18227 & 40 \\
\hline $\begin{array}{l}\text { ISO } \\
22301: 2012 * * *\end{array}$ & 3133 & 2 & 3853 & 2 & 4281 & 2 & 1506 & 4 & 1693 & 6 \\
\hline ISO 28000:2007 & - & - & 356 & 3 & 494 & 5 & 617 & 5 & 1874 & 32 \\
\hline ISO 39001:2012 & - & - & 478 & 1 & 620 & 1 & 547 & 1 & 864 & 3 \\
\hline Total & 1428391 & 6127 & $\begin{array}{c}15424 \\
16\end{array}$ & 7218 & 1520233 & 5161 & 1280928 & 6659 & 1288623 & 7142 \\
\hline
\end{tabular}

*- ISO 22000:2018 was not used in the further study due to the lack of information on its application in the hospitality industry

The major share of certifications obtained in the hospitality industry in 2019 accrues to ISO $9001(65 \%)$ and ISO 14001 (32\%), with only 3\% occupied by other standards (Figure 1). 


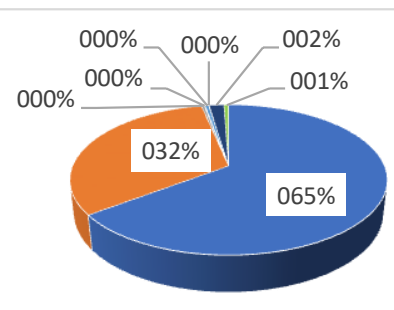

- ISO 9001:2015

- ISO 14001:2015

- ISO IEC 27001:2013

- ISO 22301:2012

- ISO 28000:2007

- ISO 39001:2012

- ISO 45001:2018

- ISO 50001:2011

Fig. 1. Distribution structure of ISO standards in the hospitality industry. Source: [14].

The analysis of the spreading dynamics among the ISO MSS standards indicates that the leading position of ISO 9001 and ISO 14001 in all sectors of the world among other groups of standards has been maintained quite steadily. A minor decrease in the rate of development may be attributed to a certain saturation of the market with these standards, as well as the already established stable organizational culture of management in many enterprises and other reasons (Franceschini F.et al.).

A similar situation is developing for ISO 9001 and ISO 14001 in the hospitality industry, which manifests slow growth since 2017 (Fig. 2).

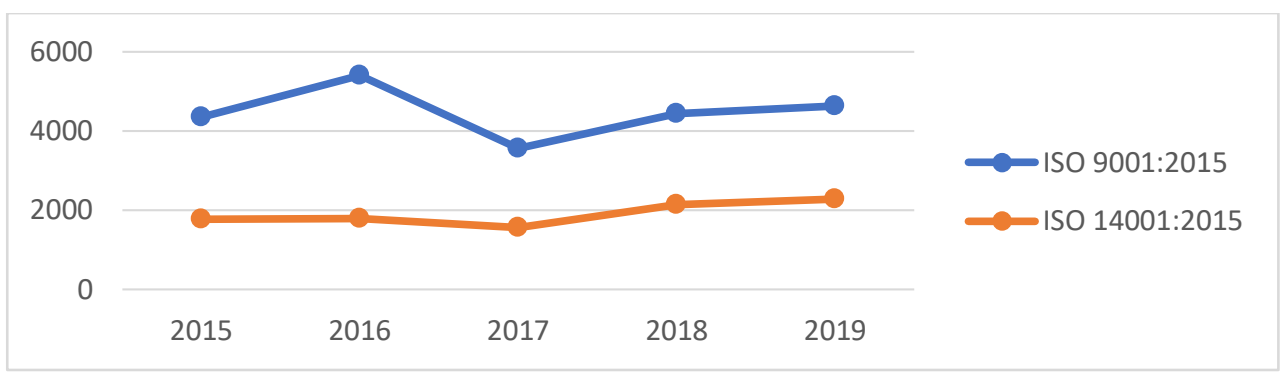

Fig. 2. Trends in the number of ISO 9001 and ISO 14001 certificates in the hospitality industry from 2015 to 2019. Source: The ISO Survey

Certain changes in standards for other groups (ISO 27001, ISO 22000:2018; ISO 22301:2012, ISO 28000:2007, ISO 39001:2012; ISO 45001, ISO 50001 (Fig. 3) have been observed, both across all industries as well as in the hospitality industry (Fig. 4).

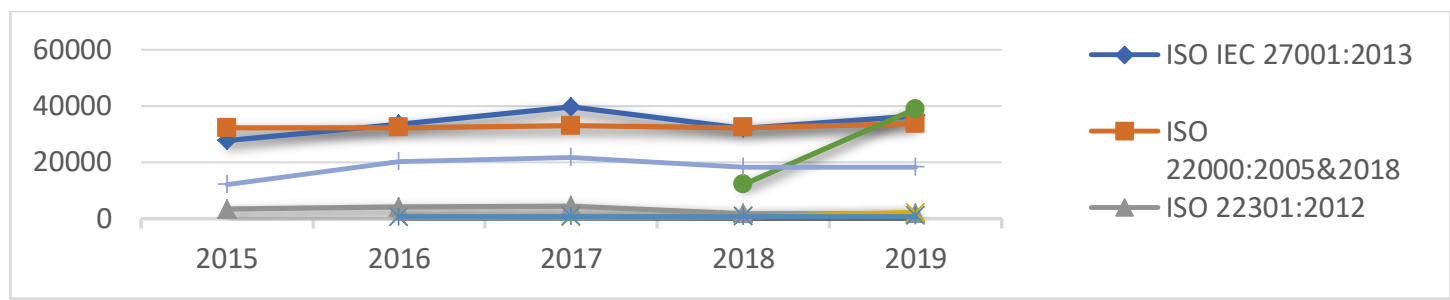

Fig. 3. Dynamics of change in the number of ISO certificates worldwide from 2015 to 2019.

Source: The ISO Survey 


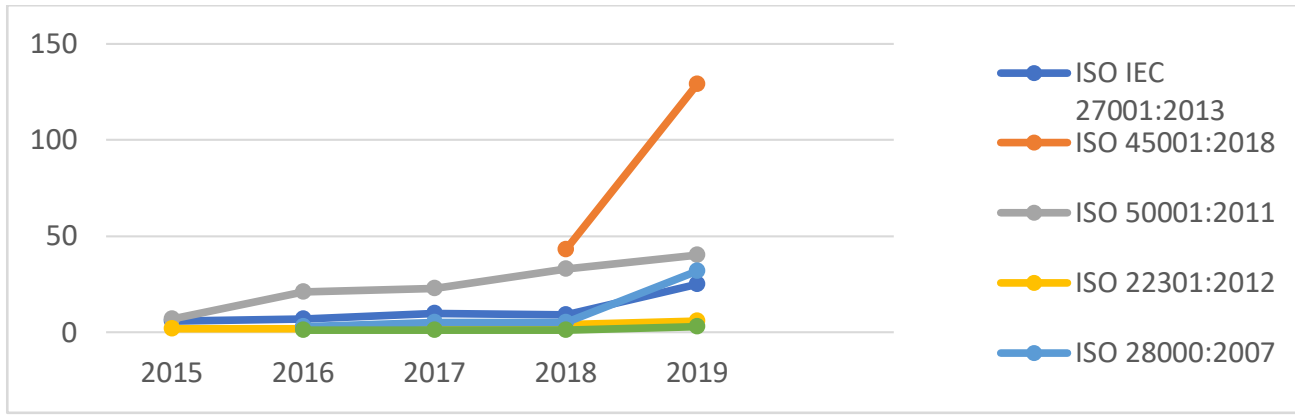

Fig. 4. Dynamics of the increase in the number of ISO certificates in the global hospitality industry from 2015 to 2019. Source: The ISO Survey

\section{Discussion}

\subsection{Correlation degree analysis}

The analysis of the correlation degree between ISO 9001 and ISO MSS in the hospitality industry has been conducted in 46 European countries. The degree of correlation has been calculated on the basis of Pearson's correlation coefficient and Cheddock's table.

The results of calculating the degree of correlation relationship between ISO 9001 and ISO

MSS in European countries in the hospitality industry, based on the analysis of a dynamic series of certificates for European countries are presented in Table 2.

Table 2. Analysis of the degree of correlation relationship between ISO 9001 and ISO MSS in European countries in the hospitality industry

\begin{tabular}{|l|c|c|c|c|c|c|}
\hline & \multicolumn{7}{|c|}{ ISO MSS Hotels and Restaurants } \\
\cline { 2 - 7 } & $\begin{array}{c}\text { ISO } \\
9001 \\
\end{array}$ & $\begin{array}{c}\text { ISO } \\
\text { (H\&I) }\end{array}$ & $\begin{array}{c}\text { ISO } \\
27001\end{array}$ & $\begin{array}{c}\text { ISO } \\
45001\end{array}$ & $\begin{array}{c}\text { ISO } \\
50001\end{array}$ & $\begin{array}{c}\text { Total ISO } \\
\text { MSS (H\&R) } \\
9-4\end{array}$ \\
\hline ISO 9001 Total/ ISO 9001(H\&R) & 0,8336 & & & & & \\
\hline ISO 9001 Total/ ISO 14001(H\&R) & & 0,9938 & & & & \\
\hline ISO 9001 Total/ ISO 45001(H\&R) & & & & 0,9573 & & \\
\hline ISO 9001 Total/ ISO 50001(H\&R) & & & & & 0,5150 & \\
\hline ISO 9001 (H\&R)/ ISO 14001(H\&R) & & 0,9226 & & & & \\
\hline ISO 9001 (H\&R)/ ISO 45001(H\&R) & & & & 0,8252 & & \\
\hline ISO 9001 (H\&R)/ ISO 50001(H\&R) & & & & & 0,4052 & \\
\hline ISO 9001 (H\&R)/ Total ISO MSS (H\&R) & & & & & & 0,9480 \\
\hline
\end{tabular}

Almost all the coefficients in the table indicate a high (0.7 to 0.9$)$ or very high (greater than 0.9) degree of correlation between ISO 9001 Total and ISO MSS to other standards, with the exception of ISO 50001, where the relationship is defined as notable (0.5 to 0.7) and moderate $(0.3$ to 0.5$)$.

The degree of correlation relationship between the dynamic range of ISO 9001 standards in general by industries and ISO 9001 in the hospitality industry is 0,8336 , which indicates a high degree of correlation. Even higher correlation is observed between ISO 9001 in the hospitality industry and the number of other MSS in this industry (0.9480).

Therefore, we can conclude that there is a direct linear high correlation relationship between the number of standards implemented in all industries and the number of standards 
for the most used management systems, with the exception of ISO 50001, where a moderately close relationship is observed. It confirms the hypothesis that the organizations that implement the basic standards for management systems ISO 9001, subsequently implement other standards, creating an integrated system, constantly improving their activities, achieving high competitiveness in the hospitality industry as well.

\subsection{Analysis of the correlation relationship degree between ISO 9001 certificates and $\mathrm{GCl}$, GII, TTCI indices}

Berényi L. points out that there is a strong correlation between the number of ISO 9001 certificates and socioeconomic indicators of European transitional economies, such as GDP per capita, exports, indicators of gross fixed capital formation, as well as the HDI index. However, this dependence is not observed with all indices. For example, the results of the analysis of the degree of correlation between the indicators of European countries in 2019 [14; 23] indicate the existence of a significant relationship only for the indicator TTCI $(0,5934)$, while the correlation with the indicators GCI/ $(0,4773)$ and GII $(0,4331)$ is characterized as moderate (Table 3$)$.

Table 3. Analysis of the correlation relationship degree between ISO 9001 and GCI, GII, TTCI

(Pearson correlation coefficient)

\begin{tabular}{|c|c|c|c|}
\hline $\begin{array}{c}\text { Correlation between the } \\
\text { indices }\end{array}$ & GCI & $\begin{array}{c}\text { GII/ } \\
2020\end{array}$ & TTCI \\
\hline ISO 9001/ GCI & 0,4773 & & \\
\hline ISO 9001/ GII & & 0,4331 & \\
\hline ISO 9001/ TTCI & & & 0,5934 \\
\hline GCI / GII & & 0,9096 & \\
\hline GCI / TTCI & & & 0,8251 \\
\hline GII / TTCI & & & 0,8790 \\
\hline
\end{tabular}

At the same time, a comparative analysis of the correlation between the Global Competitiveness Index and the Innovation Index (GCI / GII) amounts to 0.9096, which indicates a very high degree of correlation relationship. The correlation between the Global Innovation Index and the Travel \& Tourism Competitiveness Index (GCI / TTCI) is 0.8251, which lies between 0.7 and 0.9 and, therefore, is high.

Within the same range, we observe a high correlation between the Global Competitiveness Index and the Travel \& Tourism Competitiveness Index (TTCI) comprising 0.8790 (from 0.7 to 0.9 ).

\subsection{Comparative characteristics of clusters of European countries that have received certificates for ISO MSS systems in the hospitality industry}

Taking into account the materials of "The ISO Survey" website and the results of the reviewed studies, the European countries have been ranked according to the number of ISO 9001 certificates obtained by the other two factors (p. 4). Other management system standards have also been placed in accordance with the ranking of countries.

In order to perform a more objective analysis, regardless of the size of countries and the number of enterprises, the total number of ISO certificates has been calculated based on the number of the population aged 16 - 64 years, taking into account the employment rate [19]. 
The comparative characteristics of the ratio of clusters in European countries that have received certificates for ISO MSS systems in the hospitality industry are presented in Table 4.

Table 4. Comparative characteristics of clusters of European countries that have received certificates for ISO MSS in the hospitality industry. Source: [19].

\begin{tabular}{|c|c|c|c|c|c|c|c|}
\hline & \multirow[b]{2}{*}{ ISO9001 } & \multicolumn{6}{|c|}{ ISO MSS Hotels and restaurants } \\
\hline & & $\begin{array}{c}\text { ISO } \\
9001\end{array}$ & $\begin{array}{c}\text { ISO } \\
14000\end{array}$ & $\begin{array}{c}\text { ISO } \\
27001\end{array}$ & $\begin{array}{c}\text { ISO } \\
45001\end{array}$ & $\begin{array}{c}\text { ISO } \\
50001\end{array}$ & $\begin{array}{c}\text { Total } \\
(\mathrm{H} \& \mathrm{R})\end{array}$ \\
\hline \multicolumn{8}{|c|}{ Cluster 1} \\
\hline Total & 270797 & 1219 & 576 & 3 & 43 & 21 & 1862 \\
\hline$\%$ & 76,6 & 75,3 & 73,7 & 50,0 & 78,2 & 70,0 & 74,7 \\
\hline \multicolumn{8}{|c|}{ Cluster 2} \\
\hline Total & 70209 & 386 & 206 & 3 & 12 & 9 & 616 \\
\hline$\%$ & 19,8 & 23,8 & 26,3 & 50,0 & 21,8 & 30,0 & 24,7 \\
\hline \multicolumn{8}{|c|}{ Cluster 3} \\
\hline Total & 12825 & 14 & - & - & - & - & 14 \\
\hline$\%$ & 3,6 & 0,9 & - & - & - & - & 0,6 \\
\hline Total & 353831 & 1619 & 782 & 6 & 55 & 30 & 2492 \\
\hline$\%$ & 100 & 100 & 100 & 100 & 100 & 100 & 100 \\
\hline
\end{tabular}

The lion's share of certificates for management systems compliant with ISO 9001 standards falls on the European countries located in Cluster 1. The proportion of ISO 9001 certificates obtained by these countries in all industries accounts for more than $76 \%$. The specific weight of countries located in Cluster 2 is $19 \%$. The share of the remaining countries included in Cluster 3 is about $5 \%$ of all certificates. A similar pattern is observed for ISO certificates in the hospitality industry, the share of which for all certificates does not exceed 1 $\%$. Fig. 5 presents the structure of the distribution of clusters of European countries that have received certificates for ISO 9001 management systems.

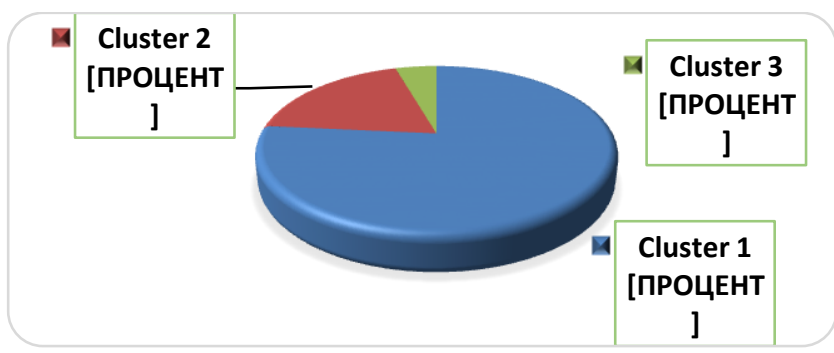

Fig. 5. Distribution of clusters of the European continent countries that have received ISO 9001 management system certificates. Source: [19].

Fig. 6 presents the structure of the cluster distribution of the European continent countries that have received certificates for ISO MSS management systems in the hospitality industry.

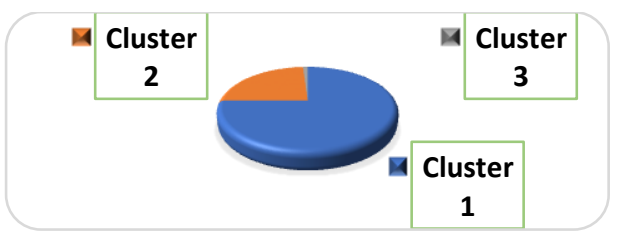

Figure 6. Structure of the cluster distribution of countries in the European region.Source: [19]. 
One of the possible reasons for the low number of ISO standards per capita in the cluster 3 countries is largely due to factors related to the characteristics of the production and organizational corporate culture, the formal approach, and the absence of real meaningful results from the implementation of standards of other management systems [20,21]. The analysis of the correlation relationship between the clusters of European countries in the hospitality industry is presented in Table 5.

Table 5. The analysis of the correlation relationship between the clusters of European countries in the hospitality industry (author's elaboration)

\begin{tabular}{|c|c|c|}
\hline Clusters & ISO 9001/1000 & ISO 9001(H\&R) \\
\hline 1 & 2 & 3 \\
\hline \multicolumn{3}{|c|}{ Cluster 1 } \\
\hline ISO 9001 Total/ ISO 9001/1000 & 0,3243 & 0,8339 \\
\hline ISO 9001 Total/ ISO 9001(H\&R) & \\
\hline ISO 9001(H\&R)/ ISO 9001/1000 Cluster 2 \\
\hline \multicolumn{2}{|c|}{0,2892} \\
\hline ISO 9001 Total/ ISO 9001/1000 Cluster 3 \\
\hline ISO 9001 Total/ ISO 9001(H\&R) & 0,7990 \\
\hline \\
\hline ISO 9001 Total/ ISO 9001/1000 & 0,5246 \\
\hline ISO 9001 Total/ ISO 9001(H\&R) & \\
\hline
\end{tabular}

The analysis of the correlation relationship between the total number of ISO certificates and ISO certificates per capita in cluster 1 indicates a weak relationship (does not confirm the presence of the tendencies identified earlier). On the other hand, there is a high degree of correlation relationship between ISO 9001 Total and ISO 9001(H\&R), as well as between ISO 9001(H\&R) and ISO 9001 per 1000 people (per capita) in the hospitality industry in cluster 1, which may have its own explanation: the hospitality industry is characterized by a closer connection. The second cluster demonstrates a less close relationship between the indicators but the hospitality industry displays a more prominent relationship as well.

The third cluster, with far fewer certificates and even fewer certified hospitality businesses, exhibits a more pronounced relationship between ISO 9001 Total and ISO 9001/1000. At the same time, there is almost no connection between the standards.

\section{Conclusions}

The findings presented in the article have led to the following conclusions.

The countries of the world and Europe have seen a slow decline in the number of ISO 9001 and ISO 14001 certifications issued between 2015 and 2019, while new ISO 27001, ISO 22000, ISO 45001, ISO 50001, ISO 22301, ISO 28000, ISO 39001 certificates have increased, including those used in the hospitality industry.

The study has confirmed the hypothesis that the more actively ISO 9001 standards are distributed in the countries, the higher their level of implementation in the hospitality industry and other ISO standards for management systems. It can be explained by the fact that the organization executives have developed a psychological readiness and acceptance of certain competitive advantages that can be brought by ISO MSS certification. The degree of ISO standards distribution can be regarded as an informal criterion of the degree of population's involvement in the technological, technical, organizational culture of society.

The greatest spread of ISO 9001 standards, as well as other MSS standards, is observed in "old" Europe, their share in the hospitality industry comprises $74.7 \%$ (cluster 1), to a much lesser extent MSS is certified in post-socialist countries $24.7 \%$ (cluster 2) and a very small 
amount $(0.6 \%)$ is in the former USSR countries (cluster 3). A particularly large discrepancy is observed in the number of ISO certificates per capita. This can be attributed to the application of different models of socioeconomic development and management systems adopted in these countries which proved to be less effective than in the countries of "old" Europe.

We can assume that the reason for the advancement of cluster 1 countries may be the fact that European countries, given their centuries-long history of democratic development of society and market relations, have formed their own European model of development, which included an appropriate mentality of people, to a greater extent ready to adopt the new philosophy, ideology, technology and tools of new management systems coming from the East (ISO MSS, Lean Production concepts, etc.). The countries (cluster 2) that joined the EU after 2004 (or candidates for accession) adopted the European model of socioeconomic development earlier, while others (cluster 3), due to internal disagreements and contradictions, postponed the processes of accession to the EU or generally preferred to follow their own model of socioeconomic development.

It should be borne in mind that for countries that follow the European path of development, an important advantage of ISO standards lies not only in their effective management system but primarily in the principles underlying them: the principles of market economy, a new philosophy and ideology, human values of survival in a changing environment.

\section{References}

1. L. Berényi, WSEAS Trans. Bus. Econ. 15, 99 (2018)

2. B. Baktybayev, J. Contemp. Gov. Public Policy 1, 1 (2020)

3. N. Deutsch, T. Drávavölgyi, and A. Rideg, Chem. Eng. Trans. 35, 655 (2013)

4. D. Holátová, M. Březinová, and L. Kantnerová, WSEAS Trans. Bus. Econ. 12, 65 (2015)

5. L. Fonseca and P. Domingues, Int. J. Qual. Res. 11, 149 (2017)

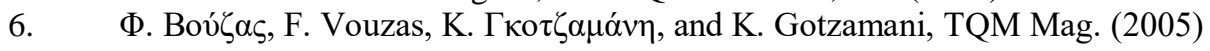

7. O. Boiral, Long Range Plann. 44, 197 (2011)

8. F. Franceschini, M. Galetto, D. Maisano, and L. Mastrogiacomo, Int. J. Qual. Reliab. Manag. 27, 558 (2010)

9. C. T. Albulescu, A. Drăghici, G. M. Fistiş, and A. Truşculescu, Procedia - Soc. Behav. Sci. 221, 278 (2016)

10. M. Bernardo, K. Gotzamani, F. Vouzas, and M. Casadesus, Total Qual. Manag. Bus. Excell. 29, 453 (2018)

11. N. Bouranta, E. Psomas, and A. Pantouvakis, TQM J. 29, 147 (2017)

12. M. M. Augustyn and J. D. Pheby, Manag. Serv. Qual. An Int. J. 10, 374 (2000)

13. N. Varotsis, J. Hosp. Tour. Manag. 8, 1 (2019)

14. M. R. Davahli, W. Karwowski, S. Sonmez, and Y. Apostolopoulos, Int. J. Environ. Res. Public Health 17, 7366 (2020)

15. F. Probáld, térszerkezetének modelljei. Szabó, Z. Dövényi, and F. Schweitzer, Budapest 159 (2005)

16. K. Lipták, Theory Methodol. Pract. 8, 33 (2012)

17. R. Stehrer, S. Leitner, M. Marcias, D. Mirza, and R. Stöllinger, WIIW Res. Rep. 409 122 (2016)

18. L. Synyayeva, D. Verba, A. Yarchuk, I. Verkhovod, and D. Aleksandrov, WSEAS Trans. Bus. Econ. 18, 531 (2021)

19. EU. Open Data Portal (n.d.)

20. 2000, Transition Economies: An IMF Perspective on Progress and Prospects (n.d.)

21. Our Mentality Is a Lean Killer /RBK. Sustainable (2018) 
Contribution of individual authors to the creation of a scientific article (ghostwriting policy)

The formulation of the main research idea, its initial hypothesis, and the statement of the goal and expected results - Victoriia Levkulych

Literature review and the identification of gaps in current studies - Victoriia Levkulych, Alexander Momot.

Determination of methodology, development of statistical methods - Victoriia Levkulych, Alexander Momot.

The database collecting - Victoriia Levkulych, Alexander Momot.

The conducting of calculations, interpretation of gained quantitative characteristics and formal verification of model parameters - Victoriia Levkulych, Alexander Momot.

The formulation of conclusions, the general critical review of the manuscript - Victoriia Levkulych, Alexander Momot.

Compliance with the WSEAS journals requirements for the article's format - Victoriia Levkulych, Alexander Momot. 